\title{
Present outlook in bronchiectasis: clinical and social study and review of factors influencing prognosis
}

\author{
DA Ellis, PE THORNLEY, AJ WIGHTMAN, M WALKER, J CHALMERS, \\ JW CROFTON \\ From the Departments of Respiratory Diseases, Medical Computing and Statistics, University of \\ Edinburgh, and the Department of Radiology, City Hospital, Edinburgh
}

ABSTRACT One hundred and sixteen patients with proven bronchiectasis diagnosed at least five years previously were studied to determine the clinical outcome, change in pulmonary function, and degree of social disability. Twenty-two patients had died and the mean duration of follow-up in the survivors was 14 years. The patients who died were characterised by a poorer initial ventilatory capacity than the survivors and cor pulmonale was present in $37 \%$ at the time of death. The survivors showed a tendency for improvement in symptoms whether treated surgically or medically. Thirty

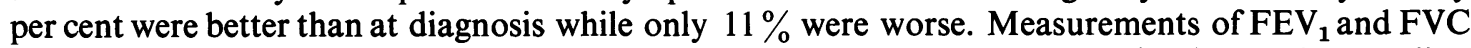
were made at diagnosis and at review, mild airways obstruction being the predominant abnormality. The change in pulmonary function was expressed as the decline in $\mathrm{FEV}_{1}$ in $\mathrm{ml} / \mathrm{yr}$. The decline in $\mathrm{FEV}_{1}$ was no greater than expected in $80 \%$ of patients and in a further $15 \%$ was of the order seen in cigarette smokers with mild airways obstruction. Poor ventilatory capacity was therefore not an important limitation in these patients. Of the survivors $77 \%$ had a good work record with less than two weeks loss of work annually from chest illness. The spouses of all married patients were interviewed at home by a trained social worker. Fifty per cent reported no social problem but $46 \%$ of spouses found the patient's cough distasteful and $29 \%$ of couples had experienced difficulties with normal sexual life. Seven per cent of the patients were severely disabled. While the overall prognosis of our patients was good a minority still have severe physical and social problems as a result of bronchiectasis.

The clinical pattern of bronchiectasis has altered in the last half century. Numerous earlier reports have described hospital inpatients with profuse foul sputum and a high mortality from pneumonia and cor pulmonale, ${ }^{1-5}$ and in 1938 Cookson and Mason entitled their paper in the Edinburgh Medical Journal "Bronchiectasis-A Fatal Disease"." Less severe forms of bronchiectasis have been recognised since then, ${ }^{7-9}$ and it is apparent that the diagnosis of bronchiectasis may cover every degree of clinical disability. Today bronchiectasis is less common because of the more effective treatment of childhood infections and pneumonia, ${ }^{10} 11$ and the more severe examples are rarely seen. Clinical impressions suggest that many patients improve considerably with non-surgical management and this is supported by published reports. ${ }^{911}$ Little is known, however,

Address for reprint requests: Dr DA Ellis, Regional Cardiothoracic Centre, Freeman Hospital, Freeman Road, High Heaton, Newcastle-upon-Tyne. about the factors which influence the severity or outcome of bronchiectasis, and long-term changes in pulmonary function have not been reported.

We have studied a group of patients with bronchiectasis, treated medically or surgically, to determine the outcome a number of years after diagnosis in terms of symptoms, pulmonary function, and social disability, and to clarify the factors which influence prognosis.

\section{Methods}

In order to achieve a follow-up of at least five years, all patients in whom a diagnosis of bronchiectasis had been made who were attending hospital between 1963 and 1972 were included in the study, provided that bronchograms were available and that the patient lived within 10 miles of the centre of Edinburgh. Fourteen patients with clear clinical evidence of relatively severe bronchiectasis and 
characteristic chest radiographic appearances in whom bronchography had not been carried out were included to avoid undue bias towards less severe cases. The initial total fulfilling these criteria was 158. A letter was sent to each patient explaining the nature of the study and inviting him to attend a special clinic. The patient was provided with a container for a 24-hour sputum collection. At the clinic one of us administered a questionnaire on current symptoms, previous health, treatment, work record, and the way in which the presence of bronchiectasis interfered with his normal way of life. The patient then completed a self-administered general health questionnaire to assess his present mental state. ${ }^{12}$ A postero-anterior chest radiograph was taken and forced expiratory volume in one second $\left(\mathrm{FEV}_{1}\right)$ and forced vital capacity (FVC) were measured using a low resistance water-filled spirometer before and 20 minutes after $200 \mu \mathrm{g}$ salbutamol given by pressurised aerosol. Breathlessness was graded 1-5 ranging from nil to severe according to the Medical Research Council questionnaire on respiratory symptoms. ${ }^{13}$ The volume of sputum produced in the previous 24 hours was measured and its purulence assessed visually. With the patient's consent, the spouse of each married patient was interviewed at home by a trained social worker, using a structured questionnaire, in order to detect any adverse social, emotional, or economic effects of chronic lung disease. Chest radiographs at the time of diagnosis and review were reported on and compared by two radiologists independently.

Of the 158 patients eligible, 41 could not be traced and one refused to take part. One hundred and sixteen patients were therefore studied, including the records of 22 who had died. Thirty-five patients had undergone surgery for bronchiectasis and 81 had received medical treatment only. The sex and age distribution at diagnosis are shown in table 1 .

Table 1 Initial age and sex distribution of patients

\begin{tabular}{lrlrl}
\hline & $\begin{array}{l}\text { Total } \\
\text { number }\end{array}$ & \multicolumn{2}{c}{ Male } & \multicolumn{2}{c}{ Female } & Mean age (range) $(y r)$ \\
\cline { 3 - 4 } & & Number $(\%)$ & Number $(\%)$ & \\
\hline Medical & 81 & $37(46)$ & $44(54)$ & $42 \cdot 2(11-66)$ \\
Surgical & 35 & $17(49)$ & $18(51)$ & $28 \cdot 7(3-61)$ \\
Total & 116 & $54(47)$ & $62(53)$ & \\
\hline
\end{tabular}

The mean interval between diagnosis by bronchography and review was 14 years (SD 6, range 5-32). The mean interval between the onset of symptoms and diagnosis by bronchography was 14.7 years (range 0-60). The mean age at onset of symptoms as related in the history was 23 years.

\section{Results}

In the following analysis we have first assessed the severity of bronchiectasis at diagnosis and examined how far this was related to various factors. We have gone on to examine the extent of improvement or deterioration determined at the follow-up examination, analysing separately those treated medically or surgically.

\section{INITIAL STATUS}

The severity of symptoms was first judged by the volume of sputum produced in 24 hours (table 2).

Table 2 Criteria for severity

\begin{tabular}{lcll}
\hline Grade & $\begin{array}{l}\text { 24-hour sputum } \\
\text { volume }(\mathrm{ml})\end{array}$ & $\begin{array}{l}\text { Breathlessness } \\
\text { grade }\end{array}$ \\
\hline Nil* & 0 & 1 \\
Mild & 10 & 1 \\
Moderate & $10-150$ & $2-3$ \\
Severe & $150+$ & $4-5$ &
\end{tabular}

Severity grade "nil" is included at review only. In addition to absence of sputum and breathlessness, the absence of cough and loss of work from chest illness in the previous year were essential criteria for this category.

This was taken from the case records at the time of diagnosis, and was measured at review. Among other possible measurements of clinical severity $\underset{\mathbb{D}}{\mathbb{Q}}$ only breathlessness (MRC grades 1-5) showed a $\vec{F}$ significant positive correlation with sputum volume $\frac{0}{3}$ $(\mathrm{p}<0.002)$. Therefore, in the 62 patients in whom the initial sputum volume was not recorded the breathlessness grade was used as the criterion of severity. This assessment, based on sputum volume 흘 or breathlessness, concurred with an overall clinical impression of severity, both our own and that of the clinician completing the initial record.

The distribution of "initial severity" in the medically and surgically treated groups is shown in $₹$ table 3. Of the 14 patients included in whom o

Table 3 Initial severity

\begin{tabular}{|c|c|c|c|c|c|}
\hline \multirow[t]{2}{*}{ Grade } & \multirow[t]{2}{*}{ Total } & \multicolumn{2}{|l|}{ Medical } & \multicolumn{2}{|l|}{ Surgical } \\
\hline & & Number & $(\%)$ & Number & $(\%)$ \\
\hline $\begin{array}{l}\text { Mild } \\
\text { Moderate } \\
\text { Severe }\end{array}$ & $\begin{array}{l}42 \\
59 \\
15\end{array}$ & $\begin{array}{l}25 \\
43 \\
13\end{array}$ & $\begin{array}{l}(31) \\
(53) \\
(16)\end{array}$ & $\begin{array}{r}17 \\
16 \\
2\end{array}$ & $\begin{array}{r}(49) \\
(46) \\
(5)\end{array}$ \\
\hline Total & 116 & 81 & (100) & 35 & (100) \\
\hline
\end{tabular}

bronchography had not been performed, eight fell into the "moderate medical" group and six into the "severe medical" group. There was no clear $\mathbb{\mathbb { D }}$ relationship between the age of onset of symptoms $\frac{?}{\mathbb{D}}$ of bronchiectasis and "initial severity". Sex and $\varrho$ presumed cause did not influence severity. Table 4 
Table 4 Presumed cause of bronchiectasis

\begin{tabular}{lc}
\hline Cause & Number of observations \\
\hline Pneumonia & 32 \\
Pertussis & 11 \\
Tuberculosis & 7 \\
"Bronchitis" & 6 \\
Measles & 3 \\
Others & 6 \\
Not known & 51 \\
Total & 116 \\
\hline
\end{tabular}

lists the presumed cause in order of frequency. The correlation between initial severity and the extent of bronchiectasis was carefully examined. Extent was measured as the number of lung segments showing bronchiectasis on the bronchograms, but areas of non-filling with contrast medium were not included. The bronchograms, therefore, may have underestimated the extent of disease. Correlation was significant when bronchograms showing more than two unfilled segments were excluded $(r=0.21$, $\mathrm{p}=<0.02)$. There was no significant relationship between initial severity and the distribution of bronchiectasis comparing predominantly upper and predominantly lower lobes or unilateral versus bilateral disease or with type of bronchiectasis.

The chest radiographic appearances showed a closer relationship with initial severity, there being a significant positive correlation between initial severity and the number of zones (0-6) showing evidence of bronchiectasis such as cystic change, parallel line shadows or crowding of lung markings $(\mathrm{r}=0.28, \mathrm{p}<0.001)$. Eleven patients $(9.5 \%)$ had normal chest films, $32(28 \%)$ showed nonspecific abnormalities only-that is, fibrosis, pleural thickening, lobar collapse, emphysema, or calcification.

In an attempt to pick out those patients with "chronic bronchitis" or "asthma" in addition to bronchiectasis the presence of one or more of the following criteria was used at review: presence of diffuse wheezes on examination; attacks of wheeze; improvement of $\mathrm{FEV}_{1}$ by more than $20 \%$ after salbutamol; treatment with corticosteroids for airways obstruction; presence of bronchial diverticula or peripheral pooling or both on bronchograms. One or more of these was present in 50 cases $(43 \%)$. It was not always easy to differentiate between chronic bronchitis and asthma; they are combined for this analysis. The grouped data showed a trend towards increasing severity with the presence of these features but this relationship was not statistically significant (table 5). When the criteria were tested individually there was a significant correlation between severity of symptoms and the presence of diffuse wheezes $(p<0.02)$, attacks of wheeze
Table 5 Distribution of patients with chronic bronchitis or asthma

\begin{tabular}{llllll}
\hline \multirow{2}{*}{$\begin{array}{l}\text { Initial } \\
\text { Severity }\end{array}$} & \multicolumn{3}{l}{ Bronchitis/asthma } & & \\
\cline { 2 - 5 } & \multicolumn{2}{l}{ Present } & & \multicolumn{2}{l}{ Absent } \\
\cline { 2 - 5 } \cline { 3 - 5 } & Number & $(\%)$ & & Number & $(\%)$ \\
\hline Mild & 15 & $(36)$ & 27 & $(64)$ \\
Moderate & 26 & $(44)$ & 33 & $(56)$ \\
Severe & 9 & $(60)$ & 6 & $(40)$ \\
Total & 50 & & 66 & \\
\hline
\end{tabular}

( $p<0.001)$, and bronchial diverticula and/or peripheral pooling $(\mathrm{p}<0.02)$.

The proportion of smokers at diagnosis was similar in each category of severity though there were more ex-smokers in the severe group. Overall only $30 \%$ of patients were smokers at diagnosis.

Initial pulmonary function tests showed that airways obstruction was the predominant ventilatory defect but in many cases this was of a mild degree, 43 patients (37\%) having an initial FEV of greater than $70 \%$ predicted. There was a significant negative correlation between initial FEV $_{1}$ and initial severity $(r=-0.17, p<0.05)$ but no correlation between initial FVC and severity $(r=-0.09, p>0.05)$, indicating increasing airways obstruction with increasing severity.

STATUS AT FOLLOW-UP

Of the 22 deaths, 16 occurred in the medically treated group and six in the surgically treated group (20\% and $17 \%$ of totals respectively). The stated cause of death was obtained from copies of death certificates. Nineteen were caused directly by the effects of chronic lung disease, two were nonrespiratory (myocardial infarction and cerebrovascular accident plus diabetes mellitus), and in one bronchiectasis was contributory (carcinoma of colon). Cor pulmonale was implicated in seven cases (all in medically treated patients) and amyloidosis was present in two. Of the five respiratory deaths in the surgically treated group two were early postoperative deaths and three were late. The mean age at death was 53.3 years (25-75) and the mean duration of symptoms of bronchiectasis was $24 \cdot 5$ years $(3-45)$.

Among the surviving patients interviewed 48 (41\%) did not change in severity, $34(29 \%)$ changed to a less severe category, and $12(10 \%)$ to a more severe category. Combining the latter group with the respiratory deaths a total of 31 patients $(27 \%)$ deteriorated (table 6).

The relationship between the "final severity" and the various factors studied is shown in table 7 . Only 20 patients $(21 \%)$ were smoking at review 
Table 6 Change in status during follow-up excluding non-respiratory deaths

\begin{tabular}{|c|c|c|c|c|c|c|c|c|c|c|c|c|}
\hline \multirow{3}{*}{$\begin{array}{l}\text { Initial } \\
\text { severity }\end{array}$} & \multirow[t]{3}{*}{ Total } & \multicolumn{11}{|c|}{ Review severity } \\
\hline & & \multicolumn{5}{|c|}{ Medical } & \multicolumn{6}{|c|}{ Surgical } \\
\hline & & Nil & Mild & Mod & Sev & $\begin{array}{l}\text { Respir } \\
\text { deaths }\end{array}$ & Nil & & Mild & Mod & Sev & $\begin{array}{l}\text { Respir } \\
\text { deaths }\end{array}$ \\
\hline $\begin{array}{l}\text { Mild } \\
\text { Moderate } \\
\text { Severe }\end{array}$ & $\begin{array}{l}41 \\
57 \\
15\end{array}$ & $\begin{array}{l}2 \\
3 \\
0\end{array}$ & $\begin{array}{r}12 \\
8 \\
2\end{array}$ & $\begin{array}{r}6 \\
21 \\
6\end{array}$ & $\begin{array}{l}1 \\
4 \\
0\end{array}$ & $\begin{array}{l}3 \\
6 \\
5\end{array}$ & $\begin{array}{l}4 \\
0 \\
0\end{array}$ & & $\begin{array}{r}12 \\
7 \\
1\end{array}$ & $\begin{array}{l}1 \\
3 \\
1\end{array}$ & $\begin{array}{l}0 \\
0 \\
0\end{array}$ & $\begin{array}{l}0 \\
5 \\
0\end{array}$ \\
\hline \multirow[b]{2}{*}{$\begin{array}{l}\text { Better } \\
\text { Same } \\
\text { Worse }\end{array}$} & 113 & 5 & 22 & 33 & 5 & 14 & 4 & & 20 & 5 & 0 & 5 \\
\hline & $\begin{array}{l}21(26 \%) \\
33(42 \%) \\
25(32 \%) \text { inc } \\
14(18 \%) \text { res } \\
\text { deaths }\end{array}$ & ng & & & & & \multicolumn{2}{|r|}{$\begin{array}{l}\text { Better } \\
\text { Same } \\
\text { Worse }\end{array}$} & \multicolumn{3}{|c|}{$\begin{array}{l}13(38 \%) \\
15(44 \%) \\
6(18 \%) \text { including } \\
5(15 \%) \text { respiratory } \\
\text { deaths }\end{array}$} & \\
\hline
\end{tabular}

Table 7 Correlation of severity of symptoms and deterioration with various factors

\begin{tabular}{|c|c|c|c|c|c|c|c|c|c|}
\hline & \multicolumn{3}{|c|}{ Initial severity } & \multicolumn{3}{|c|}{ Final severity } & \multicolumn{3}{|c|}{ Deterioration in severity } \\
\hline & $r$ & & $p$ & $r$ & & $p$ & $r$ & & $p$ \\
\hline $\begin{array}{l}\text { Extent of disease at bronchography (number of } \\
\text { involved segments excluding those with }>2 \text { unfilled) } \\
\text { Distribution-one or both lungs } \\
\text { Plain radiograph-number of zones affected } \\
\text { Smoking at diagnosis } \\
\text { Smoking at review } \\
\text { Initial FEV }_{1} \\
\text { Final FEV } 1\end{array}$ & $\begin{array}{r}0.21 \\
0.29 \\
0.17 \\
-0.17\end{array}$ & $\begin{array}{l}\text { NS } \\
\text { NS } \\
\text { NS }\end{array}$ & $\begin{array}{l}<0.02 \\
<0.001 \\
<0.05 \\
<0.05\end{array}$ & $\begin{array}{r}0.33 \\
0.21 \\
0.35 \\
\\
0.17 \\
0.20 \\
-0.21\end{array}$ & NS & $\begin{array}{l}<0.001 \\
<0.05 \\
<0.001 \\
<0.05 \\
<0.02 \\
<0.005\end{array}$ & $\begin{array}{l}0 \cdot 17 \\
0 \cdot 18\end{array}$ & $\begin{array}{l}\text { NS* } \\
\text { NS } \\
\text { NS }\end{array}$ & $\begin{array}{l}<0.05 \\
<0.05\end{array}$ \\
\hline
\end{tabular}

*Not significant.

No significant correlation of severity with: later age of first symptoms, later age at diagnosis, sex, predominantly saccular lower lobe disease, presence of chronic bronchitis or asthma, initial FVC, final FVC, decline in $\mathrm{FEV}_{1}(\mathrm{ml} / \mathrm{yr})$, percentage decline in FEV .

compared with $35(30 \%)$ at diagnosis and continued smoking was associated with a significant trend towards a deterioration in severity grade. Six of the patients still smoking $(30 \%)$ were worse at review than at diagnosis and three (15\%) better.

In the patients interviewed there was a decline in ventilatory capacity with a deterioration in breathlessness grade. Measurements of $F_{E V}$ and FVC at diagnosis and review were available for comparison in 71 patients. Fourteen $(20 \%)$ showed no change or an improvement in $\mathrm{FEV}_{1}, 43(60 \%)$ showed an annual decline of up to $50 \mathrm{ml} / \mathrm{yr}$, compared with an expected decline for normal adults of about $30 \mathrm{ml} / \mathrm{yr},{ }^{14}$ but only $14(20 \%)$ showed an annual decline of greater than $50 \mathrm{ml} / \mathrm{yr}$. There was a close correlation between final $\mathrm{FEV}_{1}$ and final severity $(\mathrm{p}=<0.005)$. The patients who died had a significantly worse initial $\mathrm{FEV}_{1}$ than the survivors $(\mathrm{p}=<0.05)$.

SOCIAL AND EMOTIONAL EFFECTS

We tried to find out in what ways the patients' lives had been affected by bronchiectasis. The spouses of the 59 married patients, 33 men and 26 women, were interviewed by the social worker in their homes.

\section{Accommodation}

Twenty-eight families $(47 \%)$ lived in ground floor accommodation only and $31(53 \%)$ in accommodation with stairs. Of those living on the ground floor, 20 patients had difficulty with stairs and six had moved to ground floor accommodation because of the patient's chest illness. Of those living in accommodation with stairs 12 had difficulty with stairs but only four had changed housing (though still with stairs) or expressed a desire to change.

\section{Extent of disability}

Nineteen patients $(32 \%)$ had difficulty with everyday tasks such as shopping, cleaning, washing, or gardening. A further five patients $(8 \%)$ were housebound (all in the medically treated group). Illness in the spouse created some difficulties in providing adequate support for the patient with bronchiectasis and vice versa. Nine spouses suffered from chronic cardiovascular or rheumatic conditions and two had psychiatric disorders. In four families the patient with bronchiectasis (two male, two female) had to perform all the household tasks because of disability in the spouse.

Family life

The spouses reaction to the patient's illness was 
generally one of acceptance and support but 27 $(46 \%)$ of the spouses expressed a dislike of the patient's cough and in nine cases $(15 \%)$ this amounted to an inability to be in the same room, especially during postural drainage. In eight families $(14 \%)$ the spouse considered that the size of the family had been influenced by the patient's chest condition and $17(29 \%)$ couples expressed difficulty with sexual intercourse as a result of the patient's symptoms. A number of female patients in the latter group had previously been advised against having a large family.

\section{Work record}

Information on occupation and work record was available for the whole group of patients interviewed (94). A change of occupation because of chest illness occurred in only 10 cases $(11 \%)$. The patients' work record is shown in table 8 .

Table 8 Patients' work records

\begin{tabular}{|c|c|c|}
\hline Work record* & Number & $(\%)$ \\
\hline 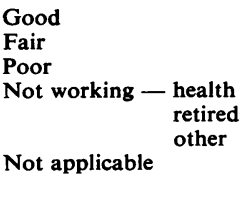 & $\begin{array}{r}72 \\
11 \\
1 \\
4 \\
2 \\
2 \\
2 \\
94\end{array}$ & $\begin{array}{r}(77) \\
(12) \\
(1) \\
(4) \\
(2) \\
(2) \\
(2) \\
(100)\end{array}$ \\
\hline
\end{tabular}

*Loss of work from chest illness in previous year: $\operatorname{good}=$ up to two weeks, fair $=$ two to six weeks, poor $=>$ six weeks.

Combining the information obtained by the social worker with the work record shows that over $70 \%$ of the patients interviewed had no social disabilities resulting from bronchiectasis.

\section{Psychiatric morbidity}

Data from the general health questionnaire revealed 17 patients (18\%) likely to have a significant neurotic disorder. Two of these patients had severe bronchiectasis and six others had received surgical treatment.

\section{Discussion}

Cough and sputum production are the classical symptoms of bronchiectasis. In order to compare its severity at different times and in different groups of patients we have used these symptoms as they were the most common complaints in our patients and we found a significant correlation between sputum volume and breathlessness. Previous reports have used the extent of bronchiectasis on bronchograms as the basis for measurement of severity, ${ }^{15}$ the degree of "physical disability",11 or unspecified criteria.

In common with all previous reports we have noted a slight preponderance of females among our cases. The trend towards increasing severity with increasing age was also shown by Sanderson ${ }^{16}$ although Field ${ }^{11}$ found no clear relationship. The presumed causes of bronchiectasis in our patients were similar to those reported previously and were unrelated to severity. Field ${ }^{11}$ noted a better prognosis with cases after tuberculosis but this was not seen in our series. We have shown a correlation between severity and extent judged by the number of involved lung segments but no clear relationship with the distribution between upper and lower lobes. Severity at review was correlated with bilateral disease. Field ${ }^{11}$ also showed some relationship between unilateral or bilateral disease and severity. $\mathrm{McKim}^{9}$ showed a fairly close correlation between extent and severity but no correlation between extent and "physical disability". Strang17 in a study of children showed some correlation between extent and severity but stressed the overriding importance of degree of infection. Clark ${ }^{18}$ also in a study of children showed no relationship with extent of disease but noted an unfavourable prognosis with upper lobe disease. Our finding of a normal chest radiograph in $9.5 \%$ of patients is in close agreement with the findings of Strang, ${ }^{17}$ Gudjberg, ${ }^{19}$ and Clark. ${ }^{18}$

One of the major problems in reviewing patients with chronic lung disease is the identification of those with coincident chronic bronchitis. We have attempted to identify such patients and have shown some relationship with severity. Chronic bronchitis clearly merges into bronchiectasis and it is not possible to identify bronchitic patients with certainty. Previous authors have reported a poor outlook in patients wth wheezing, as in our series.

During the follow-up period the trend among the surviving patients has been one of improvement in symptoms, whether the treatment was medical or surgical. Despite different methods of assessment this is in agreement with earlier reports. We have not attempted to compare the value of medical or surgical treatment because of the necessity for selection of patients for surgical treatment and the fact that many of our patients have not been reviewed regularly. Caution should be exercised in interpreting mortality statistics in such a heterogeneous group of patients studied retrospectively. Nevertheless, assuming the untraced patients were survivors, the mortality attributable to bronchiectasis cannot have been less than $12.5 \%$ over the 
total period of observation. The most important factor separating the fatal cases from the survivors was pulmonary function, the fatal cases having much worse initial ventilatory capacity. The observed changes in ventilatory capacity with age in the survivors show that in $80 \%$ the decline in $\mathrm{FEV}_{1}$ was no greater than predicted. A greater decline was noted in cigarette smokers and in those whom we considered to have chronic bronchitis. We know of no previous reports of long-term follow-up of changes in pulmonary function in bronchiectasis but several authors at single observations have found evidence of airways obstruction similar to that found in chronic bronchitis. ${ }^{20-22}$ While we would not expect a rapid deterioration in patients in our "mild" category it is reassuring to note that the rate of decline of $\mathrm{FEV}_{1}$, even in those with moderate or severe disease was not rapid, being comparable with Fletcher's heavy smokers with mild airways obstruction. ${ }^{23}$

The majority of our patients were not disabled by their disease, $77 \%$ having a good work record. This is similar to Sanderson's series ${ }^{16}$ in which $70 \%$ lost one week or less from work per annum. Most patients were married, had had children, and had no adverse emotional effects, in strong contrast to Churchill's report in $1938^{24}$ which described patients with bronchiectasis as social outcasts.

While the overall prognosis was good in our patients, $12.5 \%$ had died of respiratory disease, $10.5 \%$ had deteriorated at follow-up, and $7 \%$ were severely disabled. In $46 \%$ of the interviewed families the spouse found the patient's cough distasteful or had experienced interference with normal sexual life.

We conclude that while many of the worst effects of bronchiectasis have been mitigated by modern medical and surgical treatment, a minority of patients still have severe physical and social problems as a result of this disease. Of course all patients with bronchiectasis should be advised not to smoke.

We are grateful to Dr AC Douglas, Dr NW Horne, Mr RJM McCormack, Dr GJR McHardy, Mr D Wade, and Mr PR Walbaum for allowing us to study patients under their care, and to $\mathrm{Dr} \mathrm{CW}$ Turnbull for assistance with reading radiographs. This work was supported in part by an anonymous gift to the Department of Respiratory Diseases, University of Edinburgh.

\section{References}

${ }^{1}$ Roles FC, Todd GS. Bronchiectasis. Diagnosis and prognosis in relation to treatment. $\mathrm{Br}$ Med J 1933;2:639-43.

${ }^{2}$ Perry KMA, King DS. Bronchiectasis, a study of prognosis based on a follow-up of 400 patients. Am Rev Tuberc $1940 ; 41: 531-48$.

${ }^{3}$ Bradshaw HH, Putney FJ, Clerf LH. The fate of patients with untreated bronchiectasis. JAMA 1941;116:2561-3.

+ Ogilvie AG. The natural history of bronchiectasis. Arch Intern Med $1941 ; 68: 395-465$.

${ }^{5}$ Riggins HMcL. Bronchiectasis. Morbidity and mortality of medically treated patients. Am J Surg 1941;54:50-67.

${ }^{6}$ Cookson HA, Mason GA. Bronchiectasis-a fatal disease. Edin Med J 1938;45:844-54.

${ }^{7}$ Martin LC, Berridge FR. Bronchiectasis without disability. Lancet $1942 ; 2: 327-30$.

${ }^{8}$ Fine A, Steinhausen TB. Non-disabling bronchiectasis. Radiology 1946;46:237-43.

${ }^{9}$ McKim A. Bronchiectasis as seen in an ambulant clinic service. Am Rev Tuberc 1952;66:457-76.

${ }^{10}$ Glauser EM, Cook CD, Harris GBC. Bronchiectasis-a review of 187 cases in children with follow-up pulmonary function studies in 58. Acta Paediatr Scand 1966; Suppl 165:1-16.

${ }^{11}$ Field CE. Bronchiectasis-third report on a follow up study of medical and surgical cases from childhood. Arch Dis Child 1969;44:551-61.

${ }^{12}$ Goldberg DP. The assessment of the severity of nonpsychotic psychiatric illness by means of a questionnaire. D M Thesis. Oxford University, 1969.

${ }^{13}$ Medical Research Council. Committee on research into chronic bronchitis. Questionnaire on respiratory symptoms and instructions for its use. London: Medical Research Council, 1966.

${ }^{14}$ Cotes JE. Lung function: assessment and application in medicine. Fourth edition. Oxford: Blackwell Scientific Publications. 1979.

${ }^{15}$ Wynn-Williams N. Observations on the treatment of bronchiectasis and its relation to prognosis. Tubercle 1957;38:133-45.

${ }^{16}$ Sanderson JM, Kennedy MCS, Johnson MF, Manley DCE. Bronchiectasis: results of surgical and conservative management. A review of 393 cases. Thorax 1974; 29:407-16.

${ }^{17}$ Strang C. The fate of children with bronchiectasis. Ann Intern Med 1956;44:630-56.

${ }^{18}$ Clark NS. Bronchiectasis in childhood. Br Med J 1963; $1: 80-8$.

${ }^{19}$ Gudjberg CE. Bronchiectasis. Acta Radiol Stockh 1957; Suppl 143.

${ }^{20}$ Cherniak M, Carton RW. Factors associated with respiratory insufficiency in bronchiectasis. $\mathrm{Am} \mathrm{J} \mathrm{Med} \mathrm{1966;}$ $41: 562-71$.

${ }^{21}$ Pande JN, Jain BP, Gupta RG, Guleria JS. Pulmonary ventilation and gas exchange in bronchiectasis. Thorax $1971 ; 26: 727-33$.

${ }^{22}$ Landau LI, Phelan PD, Williams HE. Ventilatory mechanics in patients with bronchiectasis starting in childhood. Thorax 1974;29:304-12.

${ }^{23}$ Fletcher C, Peto R. The natural history of chronic airflow obstruction. Br Med J 1977;1:1645-8.

${ }^{24}$ Churchill ED. Bronchiectasis, physical and psychologic manifestations. $N$ Engl J Med 1938;218:97-101. 